\title{
Sensory characterisation of black ripe table olives from Spanish Manzanilla and Hojiblanca cultivars
}

A. López-López , A.H. Sánchez-Gómez, A. Montaño, A. Cortés-Delgado, and A. GarridoFernández

Departamento de Biotecnología de Alimentos, Instituto de la Grasa (CSIC), Campus

Universitario Pablo de Olavide, Edificio 46, Ctra. Utrera km 1, 41013 Sevilla, Spain.

*Corresponding author

E-mail address: all@cica.es (A. López-López) 


\begin{abstract}
A lexicon from the literature has been used for the characterisation of black ripe table olives from Spanish Manzanilla and Hojiblanca cultivars by Quantitative Descriptive Analysis (QDA). After confirming the acceptable reproducibility and repeatability of the panel, the descriptors that received the widest range of scores and significantly contributed to sample discrimination were: skin green, flesh green, skin sheen, flesh red, fibrousness, firmness, skin red, moisture release, fishy smell/ocean and flesh yellow. The effects of cultivar, growing area and storage period on the sensory profiles were relevant, as showed by spider graphs and multivariate methods. The map of variables, using bootstrapping techniques, associated descriptors like fibrousness, firmness, chewiness, skin red, flesh red, and skin sheen to PC1, which can then be related to texture, while PC2 was linked to skin green and astringency (related to phenols) or vinegar and fishy smell/ocean (possibly connected to cultivars). Centring data by panelist had a strong influence on the segregation of samples but increasing the number of panelists had a reduced additional effect. The diverse sensory profiles of samples were also summarised by biclustering.
\end{abstract}

Keywords: Black ripe table olives, Sensory descriptors, Sensory profile, Product characterisation, Multivariate techniques, Biclustering 


\section{Introduction}

The global table olive production is about $2.6 \times 10^{6}$ tons according to the last consolidated balance of the International Olive Council (IOC, 2018a). Most of them are processed as green Spanish-style olives $(\sim 60 \%)$; however, black ripe processing (Californian style) is progressively increasing and represents a considerable proportion of the commercialized olive products. Traditionally, California was among the most significant producers, but the problems related to wastewater handling (Garrido Fernández, Fernández Díez, \& Adams, 1997) and the increasing use of the olive crop to oil (IOC, $2018 \mathrm{~b}$ ) has stabilised its production to around $80 \times 10^{3}$ tons. Conversely, Spain is gradually becoming as one of the leading contributors to this commercial presentation $(\sim 35-40 \%$ of its table olive production).

Black ripe olive processing implies a previous storage period followed by another of darkening. Usually, the first step is achieved by immersing the fruits in brine or acidified solution (Garrido Fernández et al., 1997). However, the most critical transformation occurs during the oxidation stage, which consists of treating the olives with one to several lye solutions which penetrate progressively the flesh, followed by the subsequent washing periods to reduce the excess of alkali. During these treatments, air is bubbled through the suspension to provoke the increasingly darkening of the outer part to form a 1-2 mm brown-black ring, although the whole flesh is also affected frequently. Then, the dark colour is fixed by immersing the olives in a ferrous gluconate solution for several hours. Finally, the olives are packaged, usually in cans, which are then subjected to sterilisation since the final products is a high pH product (Garrido Fernández et al., 1997). According to 
the Trade Standards Applying to Table Olives (IOC, 2004) these olives should have sensory and texture characteristics and in agreement with their processing system.

The method for the sensory evaluation of table olives does not establish any distinction among processing styles or commercial presentations (IOC, 2011). However, it has found a wider application in the green Spanish-style than in other presentations. Furthermore, the method is focussed mainly on the commercial classification of products as demonstrated by its extensive use for this aim (Lanza, \& Amoruso, 2016; Yilmaz, \& Aydeniz, 2012). As a result, the sensory study of other presentations requires other alternatives. Galán Soldevilla, Ruíz Pérez-Cacho, \& Hernández Campuzano (2013) proposed specific descriptors (terms, definitions, and references) for adequately describing the Protected Denomination of Origin (PDO) Aloreña de Málaga table olive presentations. Furthermore, to describe the sensory profile of green Spanish-style table olives in detail, a broader 16 descriptors' list was proposed recently (López-López, Sánchez-Gómez, Montaño, Cortés-Delgado, \& Garrido Fernández, 2018). Furthermore, Lanza (2012) recently pusblished a review on the nutritional and sensory quality of table olives. Lee, Kitsawad, Sigal, Flynn, \& Guinard (2012) has also developed a more complex sensory profile sheet for the evaluation of the black ripe olives. According to these authors, many factors may influence their sensory profiles such as the fruits' characteristics and the volatile compounds (Dabbou, Issaoui, Brahmi, Nakbi, Chelab, Mechri, \& Hammani, 2012; Malheiro, Guedes de Pinho, Casal, Bento, \& Pereira, 2011; Cortés-Delgado, Sánchez, de Castro, López-López, Beato, \& Montaño, 2016). Also, the length of storage after packaging (that is, the commercialization period) may play an important role, but its specific effect has not been investigated yet. 
Also, the Quantitative Descriptive Analysis (QDA) has a broad application in many sensory food studies (Alasalvar, Pelvan, Bahar, Korel, \& Ölmez, 2012; Qin, Pan, Chen, Cheng, Hu, \& Wu, 2013; Heyman, Hopfer, \& Bershaw, 2014). Also, QDA has recently been successfully used to describe the sensory profile of ripe olives from different countries (Lee et al., 2012) and to distinguish between green Spanish-style processed cultivars and olive growing area (López-López et al., 2018). QDA has also been used for the sensory evaluation and consumer perception of some commercial Turkish green table olives (Yilmaz, \& Aydeniz, 2012).

The aim of this work was the application of a list of descriptors similar to that developed by Lee et al. (2012) to black ripe table olives from two Spanish cultivars, using QDA. The interest was mainly focused on studying the characterisation of the products according to cultivars, growing area and post-processing storage period (commercialization), but the effect of data pretreatment (centring) and the number of panelists was also checked. The analyses were achieved by ANOVA and multivariate data methods, including bootstrapping techniques.

\section{Materials and methods}

\subsection{Olives and their processing}

The olives, harvested in October 2016, were of the Manzanilla and Hojiblanca cultivars grown in different areas of Andalusia (Spain): Manzanilla, Aljarafe (Sevilla) and Lora de Estepa (Sevilla); Hojiblanca, Lora de Estepa (Sevilla) and Alameda (Málaga). By combining cultivar and growing area, the samples were coded as MAL, ML, HL and HA, respectively. 
Green olives (15 kg each cultivar) were stored in $25 \mathrm{~L}$ PVC fermenters for three months with an acidified solution containing $2.4 \%$ acetic acid before processing. Then, the fruits were subjected to darkening as follows. Olives were treated in a horizontal stainless steel cylindrical container ( $0.4 \mathrm{~m}$ diameter, $0.7 \mathrm{~m}$ length) with a lye solution of $3 \%$, which progressively penetrated the flesh until the alkali reached the pit. Next, the lye was removed, and the olives were washed with water until the $\mathrm{pH}$ reached 8.0. During the lye treatment and washing, air was injected through the bottom of the container. Finally, a $0.1 \%$ ferrous gluconate solution with $\mathrm{pH}$ corrected to 4.5 was added to fix the black color. The darkened olives were packed in jars, using a 3.5\% $\mathrm{NaCl}$ solution acidified with acetic acid to $\mathrm{pH} 4.5$ as cover brine, and the containers subjected to sterilization for $20 \mathrm{~min}$ at 130 ${ }^{\circ} \mathrm{C}$ (López-López, Rodriguez-Gómez, Cortés-Delgado, Montaño, \& Garrido-Fernández, 2009).

The sterilised products were open and sensory analysed after 30 and 210 days storage at room temperature, coded as 1(one-month storage) and 2 (seven-month storage), respectively. Therefore, the final acronyms for samples, obtained by combining cultivar, growing area and storage period, were: MAL1, MAL2, ML1, ML2, HL1, HL2, HA1 and HA2.

\subsection{Sensory analysis}

A total of 14 panelists ( 8 men and 6 women) participated in the study. They were recruited because of their participation in the habitual IG sensory analysis of table olives for decades (e.g. López-López et al., 2018) and their role in the implementation of the Sensory Analysis Method for Table Olives (IOC, 2011). To familiarise the panelists with the QDA 
techniques and the black ripe table olive descriptors (Lee et al., 2012), they were trained for 1h twice a week for two months. The references and the methodology used in this work were similar to those reported by Lee et al. (2012). In short, references for scoring appearance (skin red, skin green, skin sheen, flesh red, flesh yellow, flesh green) were selected from extreme and intermediate values found in commercial samples. The scale for aroma were obtained by mixing with the diverse proportions of the reference material with olives (e.g. vinegar for vinegary or red wine for oak barrel) or brines (e.g. salty anchovy for fishy). Similarly, the flavor scale was obtained by mixing the reference material with olives (e.g. butter with buttery) or using it in various percentages (e.g., propane gas in air for gassy) as reported previously (Lee et al., 2012). Finally, for the descriptors regarding taste and texture, the panelists had wide experience on their evaluation and scoring (López et al., 2017), although they were instructed for its application to the special case of ripe olives; besides, moisture release and residual required additional training on different intensities and comparison among cultivars. For the scoring training, industrially processed black ripe table olives from the Spanish-cultivars involved in the study were used. Initially, the panelists were asked to familiarise themselves with the product and to look for the sensory descriptors included in the evaluation sheet and make initial tentative evaluations for two weeks. Tap water was used for mouth rinsing between each sample evaluation. Finally, the panelists were allowed to familiarise themselves with the QD evaluation and practice with the unstructured scale (1, complete absence; 11, strongest perception) for another month. After these periods, the training was considered sufficient due to their previous expertise in sensory testing. 
When the period of training with reference samples ended, the panelists agreed to be familiar with the new methodology and be ready for the QDA study. The black ripe table olive samples to be tasted were then removed from the sterilized containers, tempered at room temperature and presented to panelists, who were asked to mark the intensity of the different descriptors in their scales, using the above-mentioned methodology. The samples were always presented to the panelists in standard glasses (IOC, 1987) and randomised order. Between tests, the panelists were provided with tap water to cleanse the palate. The scores of the attributes were measured with the exactitude of one decimal point and the results tabulated.

\subsection{Data analysis}

The data were analysed using the SensoMineR v.1.07 software (Husson, \& Lê, 2007). The program was designed and programmed in $\mathrm{R}$ language ( $\mathrm{R}$ Development Core Team, 2011) and collects classical methods usually applied when analysing sensory data as well as others directly conceived in the developers' laboratory. SensoMineR provides not only a synthesis of the results of the analyses of variance (ANOVA) models but also numerous easy to interpret graphical outputs. Also, special interest was paid to the generation of virtual panels, by bootstrapping techniques, for the multivariate analysis and construction of the proper confidence limits. XLSTAT (2017) and Multibiplot (Vicente Villardón, 2016) were also applied for comparison of results or specific tests.

\section{Results and discussion}

\subsection{Lexicon used}


After discussion, under the supervision of the leader, the panel agreed to retain for evaluation the 33 descriptors reported in Table 1, which is an adaptation of that developed by Lee et al. (2012) to the specific characteristics of the Spanish black ripe olive cultivars and the experimental design of this study. The list is different from that proposed for Aloreña de Málaga since many of the notes used in this case were related to the seasoning material (garlic, fennel, thyme or red pepper) (Galán Soldevilla et al., 2013), which are absent in black ripe table olives. Also, the attributes used in this study are quite different from those reported for the sensory profile study of the green Spanish-style table olives (López-López et al., 2018), in which the aroma and taste play a more relevant role. Similarly, the QDA carried out by Yilmaz, \& Aydeniz (2012) used different definitions and references for the descriptors analysed mainly regarding those related to appearance properties.

\subsection{Evaluation of samples}

The matrix of data was constituted by 336 rows ( 4 samples $\cdot 2$ storage times 14 panelists 3 replicates) and 36 columns (sample, panelist, session, and 33 descriptors). The dataset was subjected to ANOVA and multivariate analysis.

\subsubsection{Overview of results}

The scores given to the descriptors according to samples were checked for possible outliers and typing errors. Then, the revised matrix was subjected to a first overview by plotting the data as frequency histograms and boxplots since their observations may frequently show interesting trends. Two extreme shapes of histograms were observed: the first was characterised by very high frequencies at low values of scores (Fig. 1a, gassy 
smell as an example) and another with scores more evenly distributed along the scale (1-11) (Fig. 1b, skin sheen as an example). The first trend was followed by descriptors which boxes indicated low intensity or absence (Fig. 1c, gassy smell as an example) while the second corresponded to those which showed relevant scores and differences in their averages according to samples (Fig. 1d, skin sheen as an example). These graphs reveal tendencies, but the statistical inferences were deduced using ANOVA and multivariate techniques.

\subsubsection{Panel performance}

The evaluation of the panel performance is usually a first step of the sensory profile study since its proper work is essential for the reliability of the results. SensoMiner provides several tools to achieve this task. In this work, the overall panel performance was evaluated using the panelperf and panliperf functions with the appropriate ANOVA models. There were significant effects for samples (for some descriptors) and panelists (as usually observed in the sensory analysis), but not for sessions. Panelists showed a good agreement with the whole panel, had good discriminant power and showed reasonable repeatability. Therefore, overall, the panel had good reproducibility and repeatability and, subsequently, the matrix of data was reliable.

\subsubsection{Product characterisation}

\subsubsection{Sample effects}

Samples are different when at least some of the descriptors received significantly different scores. The analysis was carried out not only with SensoMineR but also with XLSTAT to contrast the results. Considering a $\mathrm{p} \leq 0.05$, the more restrictive list was 
provided by XLSTAT (Table 2). The increasing p-values mean a progressive lowest contribution to the discriminating efficiency; therefore, skin green, flesh green, skin sheen, flesh red, fibrousness, firmness, skin red, moisture release and fishy smell/ocean were the most segregating descriptors while mushroom, residual, earthy/soil, cheesy smell, and metallic should be considered similar among samples. Besides, flesh yellow, vinegary and saltiness were significant among samples according to SensoMineR. In this work, the significant descriptors would be used for distinguishing among samples but for a more comprehensive sensory profile study, only those with very low scores $(<2)$ would be removed since the rest will always be perceived in more or less intensity. To notice that the relevant descriptors were mainly related to physicochemical characteristics of skin or flesh. Only vinegary (significant in SensoMiner), possibly due to the previous to oxidation olive storage in acetic acid solutions, and fishy smell/ocean, which may be related to the degradation of some polyunsaturated fatty acids during the sterilisation process, are within the notes of aroma. Such trend may be an indication of the important removal of aroma, taste, and flavor that may occur during the vigorous and long darkening process (lye treatment and washing solutions, with continuous air bubbling) and the final intense thermal treatments of sterilization (long period at high temperature) (Garrido-Fernández et al., 1997), but also emphasises the need of an adequate selection of processing conditions. In the study carried out by Lee et al. (2012) with olives from California, Spain, Morocco, Portugal and Italy, the effect of the country was, in fact, significant for most of the descriptors, including those related to aroma, taste, and flavour. However, the most significant descriptors found in this work also received high scores by the Californian panel. 


\subsubsection{Sensory profile based on ANOVA}

\subsection{As a function of only the descriptors with discriminant power}

A first approach for the characterization of products by their sensory profiles was achieved by choosing only those descriptors with significant discriminating power. Their assessment was based on the coefficients of the ANOVA (Fig. 2 and 3), according to cultivar, growing area and storage period. MAL1 was characterized (significant coefficients) by high notes of vinegar and fishy smell/ ocean and low contributions of skin green, skin sheen, flesh red, flesh yellow, firmness, and fibrousness (Fig. 2); the sample showed interesting characteristics regarding most of the negative descriptors but not for firmness and fibrousness, which values are expected to be as high as possible. ML1 had high scores for flesh green but low for skin red; however, was low in skin sheen, flesh red, flesh yellow and fibrousness, which were also low in MAL1. Therefore, the growing area (L) affected firmness and skin green and, apparently, significantly differentiated the sensory profile of the one-month stored products. In the study carried out by Lee et al. (2012), the consumers' preference panel was able to segregate among countries but also between cultivars and within these, possibly due to diverse growing areas. MAL2 storage reduced ( $v s$ MAL1) the number of influential descriptors to only flesh green (positive connotation) and flesh red (negative) while ML2 showed a positive contribution (vs ML1) in skin green, flesh yellow, and moisture release.

The one-month stored olives from Hojiblanca cultivar (Fig. 3) showed less influence of the growing area since the coefficients for HA1 and HL1 were remarkably similar, with differential effects only for firmness, which is more degraded for olives from L growing 
area (Fig. 3). In samples from A growing area, the sensory contributions changed, disappearing in HA2 (vs HA1) the effect of skin green, skin sheen and firmness while appearing the effect of skin red, saltiness and fibrousness. In samples from growing area L, the sensory contributions also changed, disappearing in HL2 ( $v s$ HL1) the effect of skin green and skin sheen while appearing that of fishy smell/ocean, firmness and fibrousness. Overall, increasing the storage period removed the contribution of the skin green and skin sheen while caused the appearance of fibrousness, possibly due to the modification of the status of the polyphenols.

To notice the differences in the vinegar contribution, which descriptor was only found in Manzanilla. Apparently, the acetic acid used during storage might have been retained stronger by the flesh of Manzanilla than by that of Hojiblanca.

\subsubsection{Sensory profile based on all descriptors}

Although the discriminant descriptors are essential for products segregation, a wider sensory profile, including those usually found in the black ripe olives, is necessary for their characterization. Such a list may be obtained by ANOVA, estimating the average scores of all descriptors over samples (Table 3). Among those descriptors with the highest score are skin sheen and ripeness, regardless of cultivar but most of the descriptors like skin red, flesh red, flesh green, buttery, firmness, moisture release or mouth coating had appreciable levels. Finally, descriptors like artificial fruity/floral, cheese smell, sourness, rancid, and glassy smell had scores below 2, and their inclusion in the profile would be more

questionable (Table 3). In general, Hojiblanca products are high in fibrousness, firmness, flesh red, and skin sheen and those from Manzanilla in flesh green, vinegary, fishy 
smell/ocean, ripeness, or buttery after one-month storage (indicated by 1 ), with skin green also high after seven months storage (ML2). In a study on natural olives, Lanza and Amoruso (2016) found high scores for salty and bitter descriptors but low for sour because of the limited lactic acid fermentation of the tasted olives.

\subsubsection{Effect of growing area and storage on the sensory profile of samples}

The ANOVA's coefficients of descriptors can be considered as a first approach for evaluating the effects of the growing area and storage period on the sensory profile of the samples; but, the pair-wise spider graphs of samples from the same cultivar and growing area, but different storage periods, also resulted in a convenient way for the presentation of the effect of storage and growing (Fig. 4). In general, the shapes of the sensory profiles (average descriptors $<2$, excluded) did not change with time but had specific modifications according to cultivar and growing area within this. In case of MAL (Fig. 4a), storage increased the scores in skin red, skin green, skin sheen, flesh yellow, flesh green, natural fruity/floral, firmness, fibrousness, chewiness and astringency while decreased the punctuations for vinegary, alcohol, fishy smell/ocean, ripeness, buttery, metallic, and soapy. In case of ML (Fig. 4b), the changes due to storage were more reduced; but, produced an increase in the scores of skin green, flesh yellow, mushroom, oak barrel, natural fruit/floral, fibrousness, moisture, mouth coating, astringency, and residual. In HA samples (Fig. 4c), skin red, skin green, flesh yellow, natural fruity/floral and astringency increased with storage while skin sheen, briny, mushroom, earthy/soil, vinegary, fishy smell/ocean, saltiness, firmness and mouth coating decreased. In HL (Fig. 4d) only changes in skin green, and more slightly in the flesh green, fibrousness, mouth coating, chewiness and astringency were observed with time. On the other side, descriptors not mentioned, but 
included in the graph, had slight or no changes with storage. Overall, regardless of cultivar and growing area, the most outstanding effect was the increase in the scores of skin green and the reduction in vinegary after storage. Besides, Manzanilla cultivar was more prone to changes than Hojiblanca, which products, conversely, were relatively stable throughout the storage.

\subsubsection{Study of product segregation by multivariate sensory profile}

The study was made by considering the results of a virtual panel obtained by taking successive samples (bootstrapping) with replacement (500 simulations) from the real data, selecting those variables with outstanding contributions ( $p$-values $\geq 0.2$ ) and fixing a $p=0.05$ for the confidence ellipses. With the aim of evaluating the effects of variability of panelists and their numbers, the outputs from the function panelellip (SensoMineR) simulations, using the raw (I) and centred by panelist scores (II) or centred data with various panel sizes (III), were compared. The results were interpreted by projecting the variables and cases onto the plane of the first two PCs. Finally, the t-values for the Hotelling T2 tests in each simulation are also commented.

The number of eigenvalues $>1$ deduced in the PCA analysis was always 3 , but the two first Principal Components (or Dimensions, Dim.), regardless of the simulation, always explained a high variance proportion 80.53 (I), 77.14 (II) and 77.14\% (III), respectively.

Relationship among variables. The relationships among descriptors were evaluated by the projection of the most discriminant ones $(\mathrm{p} \leq 0.20)$ on the plane of the first two PCs (Fig. 5). To notice that most of the vectors always ended close to the circle, indicating a good representation in the correlation circle; also, their relationships are scarcely influenced by 
the data pretreatment or the number of panelists. In fact, the correlation among variables only slightly changed when data were centred (Fig. 5a and 5b), and the dispersion of scores at the end of the arrows only was a bit closer for the 30 members' panel (Fig. 5c). PC1 (Dim. 1) was positively associated to descriptors involving low maturation degree (fibrousness, firmness, chewiness, or skin sheen) and negatively to attributes more related to higher maturation degree (ripeness, moisture release or buttery). Therefore, in general, Dim 1 is mainly associated with texture (which also depends on maturation degree). Dim 2 is strongly related to skin green and astringency or even flesh yellow as well as, negatively, with vinegary or fishy smell/ocean, not linked among them. The close relationship between the descriptors included within texture (fibrousness, firmness or chewiness) may indicate a probable redundancy in their inclusion. Skin red and flesh red are close, meaning that both red tones, which affect different parts of the fruit, may have a similar formation. Also, buttery and fishy smell/ocean, situated very close in the correlation circle may be produced by some olive fat degradation during processing.

The proper study of these associations could reveal the causes of unpleasant notes like buttery o fishy smell/ocean or relate them to darkening conditions since microorganisms are expected to have played a limited role during the previous storage in acidic solutions of these olives (Garrido Fernández et al., 1997). To notice that most of the relationships found in these samples have been mainly associated with appearance or physicochemical conditions while Lee et al. (2012) found relevance for other descriptors associated with aroma or taste. E.g. alcohol was opposed to sour, which could mean a different previous storage system with the prevalence of yeasts over lactic acid bacteria (Garrido Fernández et al., 1997). On the contrary, terms used for the characterisation of 
cracked Aloreña de Málaga (Galán Soldevilla et al., 2013), with a substantial load of natural seasoning materials (e.g. bitterness, fennel, sour or alcohol), have nothing to do with those relevant for black ripe olives. On the contrary, some of descriptors used for the analysis of the green Spanish-style table olives from Turkish cultivars were also common to those applied in this study to black ripe olives like soapy, vinegary or bitterness (Yilmaz, \& Aydeniz, 2012).

Sensory profile of products. The gravity centres of the virtual panel perception of products were also projected onto the plane of the two first PCs. In this case, the situation of the products on the map does not change, regardless of using the original, centred data, or centred and a diverse number of panelists (Husson, Lê, \& Pagés, 2005).

Since the axes are the same PCs than for variables, the total explained variances in these plots are also the same (Fig. 6). Due to the correspondence between axes, the situation of descriptors and samples in Figures 5 and 6 may also be used to associate them. Hojiblanca is on the right of the graph (Fig. 6) and, then, the sensory profile of this cultivar may be characterised by those descriptors sharing the same orientation in Fig. 5 (fibrousness, firmness, chewiness, skin red, flesh red, or skin sheen). Initially, the highest scores were for flesh red, skin red, skin sheen, and firmness but as the storage period progresses the perceptions move to fibrousness and chewiness (Fig. 5a and 6a). In Manzanilla, the one-month stored products are perceived with notes such as vinegary, fishy smell/ocean, buttery, or briny, while the products stored for eight months were related to saltiness, ripeness, flesh green, moisture release, or skin green (Fig. 5a and 6a). 
Discrimination power. The projection of samples onto the first two PC map may allow segregating them according to cultivars and storage period. The $95 \%$ of the closest points of the generated cloud of points are used by SensoMineR to draw their confidence ellipses. A significant effect on each average point, due to the panelist variability, is expected, regardless of training (Husson et al., 2005). This has no consequences when the ANOVA analysis is carried out. However, in the PCA, the variability of panelists may influence their projections. A simple strategy to remove the effect of panelists on this projection is by centring the data by panelists. As the use of this practice is not always reported, it makes sense the evaluation of the influence of this data pretreatment on the results. When using the raw data (Fig. 6a), the segregation between samples from Manzanilla and Hojiblanca was clear, but growing areas and storage time overlapped considerably within cultivar. On the contrary, when the original data was centred by panelists, the situation changed dramatically. The areas of ellipses were reduced, their overlapping decreased markedly and, consequently, the interpretation improved (Fig. 6b). In Hojiblanca, data centring led to two independent one month stored products (associated to growing areas) with different sensory profiles; however, after eight months of storage, their sensory characteristics were homogenized to only one product, regardless of growing area (Fig. 6b). On the contrary, in Manzanilla, centering the data before analysis led to similar products after one-month storage, regardless of growing area ( $\sim 50 \%$ overlapping) while eight months storage induced significant differences linked to the growing area (Fig. 6b).

In SensoMineR, it is also possible to simulate the confidence ellipses as a function of the number of panelists. As after centring, there was still some overlapping between products according to the growing area (MAL1 vs ML1 and HA2 vs HL2), the possible 
improvement of results by using a higher number of panelists was also investigated. The use of a 30 members' panel led to an additional segregation improvement $v s$ than that obtained by just centring the data since the overlapping of the ellipses disappear, in some cases, or was reduced drastically (Fig. 6c vs 6b). In this case, not only there was segregation according to growing area in one month stored Hojiblanca and eight months stored Manzanilla but also eight-month stored Hojiblanca and one month stored Manzanilla were better discriminated (had a reduced ellipses’ overlapping).

The pair-wise dissimilarities among the diverse black ripe olive products were subjected to the Hotelling's 2 tests (Table 4). The significant differences obtained, based on the p-values were in agreement with the confidence ellipses above-commented. In the case of working with raw data, there were found 8 non-significant differences (Table 4a) while centring the data and centring plus using 30 panelists, reduced the number of nonsignificant differences to three (Table 4b) and only two (HA2 vs HL2; MAL1 vs ML1) (Table 4c), respectively. Therefore, this test confirmed that the removal of the effects of panelists by centring resulted essentially for a proper interpretation while the additional effect of incrementing of the number of panelists was less effective and probably would not compensate the supplementary effort required.

Hence, the multivariate analysis has demonstrated to be a powerful tool to evaluate the influence of data pretreatment and the number of panelists on the interpretation of results as well as to identifying the sensory profiles of black ripe olives according to cultivar, growing area, and storage, which could be of interest for producers. These results are in agreement with those obtained by Lee et al. (2012), who found that the growing area may markedly influence the preferences of the US consumers (the main Spanish market for 
black ripe olives). In such investigation, the negative drivers for liking were alcohol, oak barrel and artificial fruity/floral (none of them relevant in this work). However, one of the segments of consumers who systematically preferred olives from California was also negatively influenced by rancid which could be associated with the buttery or fishy smell/ocean notes found in this work. Galán Soldevilla et al. (2013) reported, also applying PCA, good discrimination among the three main Aloreña de Málaga presentations, associating the Fresh Green to bitter, the Traditional with wood and the Cured with sour (due to the lactic acid produced during the previous to packaging storage). PCA also separated green olives in defected and un-defected samples, with the highest loading in both cases being related to kinesthetic sensations (Lanza et al., 2016).

\subsubsection{Segregation by bi-clustering}

A complete visual overview of profiles as a function of the sensory descriptors (average score $>2$ to facilitate readability), growing area, and storage time can be observed by a bi-cluster graph (Fig. 7). The analysis formed three main clusters: i) one month stored Hojiblanca from A (HA1); ii) one month stored Hojiblanca from L (HL1) plus eight months stored Hojiblanca from L and A (HL2 and HA2) and eight months stored Manzanilla from AL and L (MAL2 and ML2); and iii) one month stored Manzanilla from L and AL (ML1 and MAL1). The individual consideration of Cluster 1 (HA1) was, apparently, caused mainly because of its higher scores in mouth coating, bitterness, earthy soil and mushroom (Cluster c, descriptors); but, HA1 has the same scores than HL1 regarding skin green, flesh red, moisture, or flesh green and some similarity with attributes like skin sheen, firmness, fibrousness, alcohol, or vinegary (Fig. 7). To notice also the segregation of one month stored Manzanilla, regardless of growing area, as a different 
cluster (Cluster 3), mainly due to its high scores in fishy, buttery, ripeness and briny but low in astringency, natural fruity/floral, flesh yellow, oak barrel and fibrousness. However, in this analysis, the eight months stored Manzanilla from L and AL (ML2 and MAL2) had similarity with the stored Hojiblanca (HA2 and HL2 plus HL1) since are included in the same cluster (Cluster 2), indicating that apparently, the eight months storage has approached the sensory profiles from both cultivars. The Cluster 2 is mainly characterized by its high scores in astringency, natural fruity/floral, or flesh yellow and low in fishy,

vinegary, alcohol, soapy, mushroom, or earthy/soil smell. The graph also allows the visual observation by the reader of any other specific difference between clusters or within them that could be of interest to him/her. Therefore, bi-clustering was another approach that may contribute not only to segregate among cultivars, growing area or storage time but also to identify the sensory profile of the different products and to visualise their most relevant changes at a glance.

\section{Conclusion}

The sensory profiles of the Spanish cultivars Manzanilla and Hojiblanca black ripe olives were studied by Quantitative Descriptive Analysis, using an adaptation of the lexicon developed by Lee et al. (2012). The descriptors that mainly contributed to segregation between samples were: skin green, flesh green, skin sheen, flesh red, fibrousness, firmness, skin red, moisture release, fishy smell/ocean, and flesh yellow. The effects of storage within olive growing area were noticeable and visualized by spider graphs while the variable and products were projected onto the first two Principal Components, using bootstrapping techniques, and allowed associating descriptors, descriptors and products, or segregating products. For improving the interpretation of results, the removal of the panelist 
effects before the multivariate analysis was essential and more transcendent than the increase in the number of panelists. Its application and explicit mention in the sensory analysis publications should be emphasised, even considering that, usually, this data pretreatment is routinary applied by the program, since, frequently, the researcher is not aware of its convenience and need.

\section{Acknowledgements}

This work was supported in part by the Ministry of Economy and Competitiveness from the Spanish government through Project AGL2014-54048-R, partially financed by the European Regional Development Fund (ERDF). We also thank Elena Nogales Hernández for her technical assistance.

\section{References}

Alasalvar, C., Pelvan, E., Bahar, B., Korel, F., \& Ölmez, H. (2012). Flavour of natural and roasted Turkish hazelnut varieties (Corylus avellana L.) by descriptive sensory analysis, electronic nose and chemometrics. International Journal of Food Science and Technology, $47,122-131$

Cortés-Delgado, A., Sánchez, A.H., de Castro, A., López-López, A., Beato, V.M., \& Montaño, A. (2016). Volatile profile of Spanish-style green table olives prepared from different cultivars grown at different locations. Food Research International, 83, 131-142.

Dabbou, S., Issaoui, M., Brahmi, F., Nakbi, A., Chelab, H., Mechri, R., \& Hammani, M. (2012). Changes in volatile compounds during processing of Tunisian-style table olives. Journal of the American Oil Chemists' Society, 89, 347-354. 
Galán Soldevilla, H., Ruiz Pérez-Cacho, P., \& Hernández Campuzano, J.A. (2013). Determination of the sensory profiles of Aloreña table olives. Grasas y Aceites, 64, 442452.

Garrido Fernández, A., Fernández Díez, M.J., \& Adams, R.M. (1997). Table olive production and processing. London: Chapman \& Hall.

Heyman, H., Hopfer, H., \& Bershaw, D. (2014). An exploration of the perception of minerality in white wines by projective mapping and descriptive analysis. Journal of Sensory Studies, 29, 1-13.

Husson, F., \& Lê, S. (2007). SensoMineR: Sensory data analysis with R. R package version 1.07. http://agrocampus-rennes.fr/math/SensoMinR (Accessed 15.06.17).

Husson, F., Lê, S., \& Pagés, J. (2005). Confidence ellipse for the sensory profiles obtained by principal components analysis. Food Quality and Preference, 16, 245-250.

IOC, International Olive Council. (2018a). Online reference included in World table olives figures: production. http://www.internationaloliveoil.org/estaticos/view/132-world-tableolive-figures (Accessed 30-04-18).

IOC, International Olive Council. (2018b). Online reference included in World olive oil figures: production. http://www.internationaloliveoil.org/estaticos/view/132-world-oliveoil-figures (Accessed 30-04-18).

IOC, International Olive Council. (2004). Trade standards applying to table olives. IOC/OT/NC No. 1. Madrid, Spain: International Olive Council. 
IOC, International Olive Council. (2011). Method for the sensory analysis of table olives. COI/OT/MO No 1 /Rev.2 November 2011. Madrid, Spain: International Olive Council. http://www.internationaloliveoil.org/estaticos/view/70-metodos-de-evaluacion (Accessed 15-06-17).

IOC, International Olive Council. (1987). Sensory analysis of olive oil standard glass for oil tasting. COI/T20/Doc No 5. Madrid, Spain: International Olive Council.

Lanza, B. (2012). Nutritional and sensory quality of table olives. In I. Muzzalupo (Ed), Olive Germplasm. The Olive Cultivation, Table Olive and Olive Oil Industry in Italy. IntechOpen (Chapter 16). http://dx.doi.org/10.5772/51723.

Lanza, B., \& Amoruso, F. (2016). Sensory analysis of natural table olives: Relationships between appearance of defect and gustatory-kinaesthetic sensations changes. LWT-Food Science and Technology, 68, 365-372.

Lee, S.M., Kitsawad, K., Sigal, A., Flynn, D., \& Guinard, J.X. (2012). Sensory properties and consumer acceptance of imported and domestic sliced black ripe olives. Journal of Food Science, 77, S439-S448.

López-López, A., Rodríguez-Gómez, F., Cortés-Delgado, A., Montaño, A., \& GarridoFernández, A. (2009). Influence of ripe table olive processing on oils characteristics and composition as determined by chemometrics. Journal of Agricultural and Food Chemistry, $57,8973-8981$. 
López-López, A., Sánchez-Gómez, A.H., Montaño, A., Cortés-Delgado, A., \& GarridoFernández, A. (2018). Sensory profile of Green Spanish-style table olivesaccording to cultivar and origin. Food Research International, 108, 347-356.

Malheiro, R., Guedes de Pinho, P., Casal, S., Bento, A., \& Pereira, J.A. (2011). Determination of the volatile profile of stoned table olives from different varieties by using HS-SPME and GC/IT-MS. Journal of the Science of Food and Agriculture, 91, 1693-1701.

Qin, Z, Pang, X, Chen, D., Cheng, H., Hu, X, \& Wu, J. (2013). Evaluation of Chinese tea by the electronic nose and gas chromatography-mass spectrometry: Correlation with sensory properties and classification according to grade level. Food Research International, $53,864-874$.

R Development Core Team (2011). R: A language and environment for statistical computing. Vienna, Austria: The R Foundation for Statistical Computing. ISBN-3-90005107-0. (Accessed 15-06-17).

Vicente Villardón, J.L. (2016). Multibiplot: A package for Multivariate Analysis using Biplots. Departamento de Estadística, Universidad de Salamanca. http://biplot.usal.es/ClassicalBiplot/index.htlm (Accessed April 2018).

XLSTAT (2017). Data Analysis and Statistical Solution for Microsoft Excel. Addinsoft, Paris, France.

Yilmaz, E., \& Aydeniz, B. (2012). Sensory evaluation and consumer perception of some commercial green table olives. British Food Journal, 114, 1085-1094. 


\section{Figure captions}

Figure 1. Examples of histograms and box plots to illustrate the two extreme trends observed for the average scores of descriptors in the study of the sensory profile of black ripe table olives. Notes: HA1 (cultivar, Hojiblanca; growing area, Alameda (Málaga); storage period, one month), HA2 (Hojiblanca; Alameda; seven months), HL1 (Hojiblanca; Lora de Estepa (Sevilla); one month), HL2 (Hojiblanca; Lora de Estepa (Sevilla); seven months), MAL1 (Manzanilla; Aljarafe (Sevilla); one month), MAL2 (Manzanilla; Aljarafe (Sevilla); seven months), ML1 (Manzanilla; Lora de Estepa (Sevilla); one month), ML2 (Manzanilla; Lora de Estepa (Sevilla); seven months).

Figure 2. Study of the sensory profile of black ripe table olives using ANOVA model with discriminant power descriptors (XLSTAT and SensoMineR). Notes: MAL1 (cultivar, Manzanilla; growing area, Aljarafe (Sevilla); storage period, one month), MAL2 (Manzanilla; Aljarafe (Sevilla); seven months), ML1 (Manzanilla; Lora de Estepa (Sevilla); one month), ML2 (Manzanilla; Lora de Estepa (Sevilla); seven months).

Figure 3. Study of the sensory profile of black ripe table olives using ANOVA model with discriminant power descriptors (XLSTAT and SensoMineR). Notes: HA1 (cultivar, Hojiblanca; growing area, Alameda (Málaga); storage period, one month), HA2 (Hojiblanca; Alameda; seven months), HL1 (Hojiblanca; Lora de Estepa (Sevilla); one month), HL2 (Hojiblanca; Lora de Estepa (Sevilla); seven months). 
Figure 4. Spider graphs of the sensory profile of black ripe table olives according to cultivars, origin, and storage period (descriptors with averages $\geq 2$ ). Notes: HA1 (cultivar, Hojiblanca; growing area, Alameda (Málaga); storage period, one month), HA2 (Hojiblanca; Alameda; seven months), HL1 (Hojiblanca; Lora de Estepa (Sevilla); one month), HL2 (Hojiblanca; Lora de Estepa (Sevilla); seven months), MAL1 (Manzanilla; Aljarafe (Sevilla); one month), MAL2 (Manzanilla; Aljarafe (Sevilla); seven months), ML1 (Manzanilla; Lora de Estepa (Sevilla); one month), ML2 (Manzanilla; Lora de Estepa (Sevilla); seven months).

Figure 5. Correlation circle obtained by multivariate analysis, using several simulation conditions and bootstrapping techniques: a) using the raw data b) centred data according to panelists, and c) centred data supposing a panel of 30 panelists. Notes: HA1 (cultivar, Hojiblanca; growing area, Alameda (Málaga); storage period, one month), HA2 (Hojiblanca; Alameda; seven months), HL1 (Hojiblanca; Lora de Estepa (Sevilla); one month), HL2 (Hojiblanca; Lora de Estepa (Sevilla); seven months), MAL1 (Manzanilla; Aljarafe (Sevilla); one month), MAL2 (Manzanilla; Aljarafe (Sevilla); seven months), ML1 (Manzanilla; Lora de Estepa (Sevilla); one month), ML2 (Manzanilla; Lora de Estepa (Sevilla); seven months).

Figure 6. Maps of samples distribution obtained by multivariate analysis, using in several simulation conditions and bootstrapping techniques: a) using the raw data b) centred data according to panelists, and c) centred data supposing a panel of 30 panelists. Notes: HA1 (cultivar, Hojiblanca; growing area, Alameda (Málaga); storage period, one month), HA2 
(Hojiblanca; Alameda; seven months), HL1 (Hojiblanca; Lora de Estepa (Sevilla); one month), HL2 (Hojiblanca; Lora de Estepa (Sevilla); seven months), MAL1 (Manzanilla; Aljarafe (Sevilla); one month), MAL2 (Manzanilla; Aljarafe (Sevilla); seven months), ML1 (Manzanilla; Lora de Estepa (Sevilla); one month), ML2 (Manzanilla; Lora de Estepa (Sevilla); seven months).

Figure 7. Bi-cluster of the sensory profiles of black ripe table olives according to cultivars, growing area, storage period, and descriptors (average score $>2$ ). Notes: HA1 (cultivar, Hojiblanca; growing area, Alameda (Málaga); storage period, one month), HA2 (Hojiblanca; Alameda; seven months), HL1 (Hojiblanca; Lora de Estepa (Sevilla); one month), HL2 (Hojiblanca; Lora de Estepa (Sevilla); seven months), MAL1 (Manzanilla; Aljarafe (Sevilla); one month), MAL2 (Manzanilla; Aljarafe (Sevilla); seven months), ML1 (Manzanilla; Lora de Estepa (Sevilla); one month), ML2 (Manzanilla; Lora de Estepa (Sevilla); seven months). 
Table 1

Descriptors used for the evaluation of the sensory profile of black ripe olives from Manzanilla and Hojiblanca Spanish cultivars by Quantitative Descriptive Analysis (QDA).

\begin{tabular}{|c|c|}
\hline Sensory attribute & Definition \\
\hline Skin red & Black-reddish brown color \\
\hline Skin green & Black-greenish gray color \\
\hline Skin sheen & The vividness vs. dullness of the olive skin \\
\hline Flesh red & Black-reddish brown color \\
\hline Flesh yellow & Black-yellow color \\
\hline Flesh green & Black-greenish gray color \\
\hline Briny & Aroma of pickling salt \\
\hline Mushroom & Aroma of sautéed and cooked mushrooms \\
\hline Earthy/Soil & Aroma of natural wet soil \\
\hline Oak barrel & Aroma of wood \\
\hline Nutty & Aroma of peanut \\
\hline Artificial fruity/Floral & Scent of artificial fruit flavor (e.g. raspberry) \\
\hline Natural fruity/Floral & Mild scent of natural fruit/flower (e.g. chrysanthemum) \\
\hline Vinegary & Aroma of vinegar \\
\hline Alcohol & Aroma of ethanol \\
\hline Fishy smell/Ocean & Aromas of the ocean and of dried anchovy \\
\hline Cheesy smell & Aroma of feta cheese \\
\hline Sourness & Taste of citric acid \\
\hline Bitterness & Taste of caffeine \\
\hline Saltiness & Taste of sodium chloride \\
\hline Ripeness & Sensation of green and unripe vs. ripe olives \\
\hline Buttery & Sensations related to high fat/oil content \\
\hline Metallic & Sensations related to canned vegetables \\
\hline Rancid & Unpleasant flavor as a result of being stale \\
\hline Soapy smell/Medicinal & Sensation related to products containing soap \\
\hline Gassy smell & Sensation related to propane gas \\
\hline Firmness & Force of first bite manifested by resistance to deformation \\
\hline Fibrousness & Texture of some raw vegetables (e.g. celery) \\
\hline Moisture release & Amount of moisture released during chewing \\
\hline Mouth coating & Amount of mouth coating due to oil \\
\hline Chewiness & Amount of time required to chew before swallowing \\
\hline Astringency & Dry, puckering sensation on the tongue and palate \\
\hline Residual & Amount of particles left after swallowing \\
\hline
\end{tabular}




\section{Table 2}

Discriminating power by descriptor in the analysis of the sensory profile of black ripe olives from Manzanilla and Hojiblanca Spanish cultivars, using QDA.

\begin{tabular}{lcc}
\hline \multicolumn{1}{c}{ Descriptors } & Test values & p-values \\
\hline Skin green & 5.568 & 0.000 \\
Flesh green & 5.018 & 0.000 \\
Skin sheen & 4.048 & 0.000 \\
Flesh red & 3.979 & 0.000 \\
Fibrousness & 2.553 & 0.005 \\
Firmness & 2.418 & 0.008 \\
Skin red & 1.841 & 0.033 \\
Moisture release & 1.751 & 0.040 \\
Fishy smell/Ocean & 1.713 & 0.043 \\
Flesh yellow & 1.628 & 0.052 \\
Vinegary & 1.140 & 0.127 \\
Astringency & 0.841 & 0.200 \\
Ripeness & 0.759 & 0.224 \\
Soapy smell/Medicinal & 0.742 & 0.229 \\
Briny & 0.628 & 0.265 \\
Saltiness & 0.461 & 0.322 \\
Natural fruity/Floral & 0.427 & 0.335 \\
Chewiness & 0.309 & 0.379 \\
Rancid & 0.278 & 0.391 \\
Bitterness & 0.001 & 0.500 \\
Alcohol & -0.044 & 0.518 \\
Buttery & -0.064 & 0.526 \\
Sourness & -0.161 & 0.564 \\
Nutty & -0.265 & 0.604 \\
Artificial fruity/Floral & -0.513 & 0.696 \\
Mouth coating & -0.577 & 0.718 \\
Oak barrel & -0.613 & 0.730 \\
Gassy smell & -0.701 & 0.758 \\
Mushroom & -0.759 & 0.776 \\
Residual & -1.120 & 0.869 \\
Earthy/Soil & -1.160 & 0.877 \\
Cheesy smell & -1.357 & 0.913 \\
Metallic & -1.852 & 0.968 \\
\hline
\end{tabular}


Table 3

Sensory profile of black ripe olives from Manzanilla and Hojiblanca Spanish cultivars. Average scores of the samples (standard error, in parenthesis), according to descriptors. Notes: HA1 (cultivar, Hojiblanca; growing area, Alameda (Málaga); storage period, one month), HA2 (Hojiblanca; Alameda; seven months), HL1 (Hojiblanca; Lora de Estepa (Sevilla); one month), HL2 (Hojiblanca; Lora de Estepa (Sevilla); seven months), MAL1 (Manzanilla; Aljarafe (Sevilla); one month), MAL2 (Manzanilla; Aljarafe (Sevilla); seven months), ML1 (Manzanilla; Lora de Estepa (Sevilla); one month), ML2 (Manzanilla; Lora de Estepa (Sevilla); seven months).

\begin{tabular}{|c|c|c|c|c|c|c|c|c|}
\hline Descriptor & MAL1 & MAL2 & ML1 & $\mathrm{ML2}$ & HL1 & $\mathrm{HL2}$ & HA1 & HA2 \\
\hline Skin red & $3.84(0.50)$ & $4.46(0.46)$ & $3.28(0.39)$ & $3.47(0.41)$ & $4.65(0.50)$ & $4.95(0.47)$ & $4.42(0.48)$ & $5.21(0.44)$ \\
\hline Skin green & $2.23(0.26)$ & $3.56(0.43)$ & $3.88(0.43)$ & $5.75(0.38)$ & $1.80(0.21)$ & $3.21(0.40)$ & $1.82(0.22)$ & $3.53(0.40)$ \\
\hline Skin sheen & $4.57(0.36)$ & $5.50(0.37)$ & $4.19(0.30)$ & $4.21(0.24)$ & $6.14(0.41)$ & $5.88(0.35)$ & $6.47(0.40)$ & $5.40(0.31)$ \\
\hline Flesh red & $2.79(0.44)$ & $2.66(0.31)$ & $2.45(0.38)$ & $2.69(0.33)$ & $4.60(0.50)$ & $4.48(0.46)$ & $4.67(0.45)$ & $4.83(0.45)$ \\
\hline Flesh yellow & $1.95(0.22)$ & $2.81(0.28)$ & $2.13(0.24)$ & $3.37(0.35)$ & $2.66(0.30)$ & $3.13(0.36)$ & $2.44(0.28)$ & $3.18(0.40)$ \\
\hline Flesh green & $4.03(0.48)$ & $5.08(0.42)$ & $4.66(0.46)$ & $4.48(0.36)$ & $2.15(0.29)$ & $2.45(0.29)$ & $2.16(0.27)$ & $2.32(0.23)$ \\
\hline Briny & $3.78(0.40)$ & $3.82(0.38)$ & $3.75(0.35)$ & $3.40(0.26)$ & $3.25(0.34)$ & $3.23(0.33)$ & $3.61(0.33)$ & $2.85(0.33)$ \\
\hline Mushroom & $2.62(0.29)$ & $2.31(0.28)$ & $2.29(0.21)$ & $2.78(0.29)$ & $2.39(0.24)$ & $2.35(0.25)$ & $2.82(0.31)$ & $2.36(0.21)$ \\
\hline Earthy/soil & $2.09(0.23)$ & $1.97(0.20)$ & $2.07(0.16)$ & $2.14(0.20)$ & $1.85(0.13)$ & $2.09(0.26)$ & $2.33(0.29)$ & $2.06(0.20)$ \\
\hline Oak barrel & $2.40(0.28)$ & $2.17(0.26)$ & $2.18(0.27)$ & $2.57(0.32)$ & $2.60(0.32)$ & $2.75(0.37)$ & $2.30(0.27)$ & $2.42(0.32)$ \\
\hline Nutty & $1.89(0.19)$ & $2.07(0.21)$ & $1.61(0.13)$ & $1.96(0.16)$ & $1.87(0.20)$ & $2.06(0.20)$ & $2.02(0.20)$ & $2.18(0.26)$ \\
\hline Artificial fruity/Floral & $1.68(0.17)$ & $1.60(0.15)$ & $1.55(0.17)$ & $1.73(0.16)$ & $1.58(0.17)$ & $1.10(0.15)$ & $1.89(0.26)$ & $1.80(0.20)$ \\
\hline Natural fruity/Floral & $2.04(0.25)$ & $2.61(0.24)$ & $2.07(0.24)$ & $2.57(0.26)$ & $2.33(0.28)$ & $2.47(0.29)$ & $2.09(0.21)$ & $2.42(0.25)$ \\
\hline Vinegary & $2.25(0.36)$ & $1.46(0.11)$ & $2.12(0.25)$ & $1.47(0.12)$ & $2.01(0.29)$ & $1.55(0.14)$ & $2.01(0.24)$ & $1.57(0.15)$ \\
\hline Alcohol & $2.14(0.30)$ & $1.82(0.25)$ & $1.79(0.25)$ & $1.71(0.22)$ & $1.92(0.28)$ & $1.91(0.26)$ & $1.94(0.31)$ & $1.84(0.28)$ \\
\hline Fishy smell/ocean & $2.11(0.23)$ & $1.57(0.19)$ & $1.72(0.19)$ & $1.50(0.12)$ & $1.60(0.20)$ & $1.35(0.10)$ & $1.85(0.19)$ & $1.48(0.14)$ \\
\hline Cheese smell & $1.48(0.13)$ & $1.58(0.16)$ & $1.45(0.18)$ & $1.38(0.09)$ & $1.40(0.11)$ & $1.47(0.11)$ & $1.38(0.10)$ & $1.54(0.15)$ \\
\hline Sourness & $2.00(0.30)$ & $1.83(0.19)$ & $1.98(0.24)$ & $1.95(0.22)$ & $1.91(0.21)$ & $1.60(0.14)$ & $1.84(0.20)$ & $1.62(0.17)$ \\
\hline Bitterness & $2.34(0.32)$ & $2.11(0.22)$ & $2.61(0.32)$ & $2.70(0.30)$ & $2.26(0.26)$ & $2.30(0.26)$ & $2.70(0.35)$ & $2.55(0.28)$ \\
\hline Saltiness & $2.79(0.29)$ & $3.00(0.31)$ & $2.69(0.30)$ & $2.95(0.26)$ & $2.69(0.26)$ & $2.42(0.24)$ & $2.73(0.31)$ & $2.03(0.22)$ \\
\hline Ripeness & $5.71(0.45)$ & $5.21(0.45)$ & $5.11(0.43)$ & $5.14(0.41)$ & $4.71(0.39)$ & $4.56(0.42)$ & $4.50(0.37)$ & $4.96(0.41)$ \\
\hline Buttery & $4.28(0.41)$ & $3.47(0.42)$ & $3.89(0.32)$ & $3.33(0.37)$ & $3.55(0.34)$ & $3.55(0.38)$ & $3.27(0.30)$ & $3.35(0.37)$ \\
\hline Metallic & $2.54(0.33)$ & $2.13(0.20)$ & $2.28(0.22)$ & $2.19(0.22)$ & $2.09(0.22)$ & $2.22(0.25)$ & $1.93(0.18)$ & $2.17(0.21)$ \\
\hline Rancid & $1.59(0.23)$ & $1.51(0.20)$ & $1.32(0.13)$ & $1.43(0.16)$ & $1.34(0.13)$ & $1.29(0.11)$ & $1.39(0.13)$ & $1.54(0.19)$ \\
\hline Soapy & $2.36(0.33)$ & $1.83(0.27)$ & $1.80(0.22)$ & $1.85(0.28)$ & $1.82(0.22)$ & $1.94(0.32)$ & $1.96(0.26)$ & $1.88(0.23)$ \\
\hline Glassy smell & $1.29(0.10)$ & $1.33(0.11)$ & $1.30(0.30)$ & $1.21(0.06)$ & $1.30(0.11)$ & $1.35(0.11)$ & $1.38(0.16)$ & $1.31(0.09)$ \\
\hline Firmness & $3.40(0.30)$ & $3.82(0.32)$ & $3.92(0.32)$ & $3.50(0.26)$ & $4.64(0.38)$ & $4.73(0.31)$ & $4.89(0.31)$ & $4.36(0.27)$ \\
\hline Fibrousness & $2.37(0.25)$ & $3.04(0.31)$ & $2.57(0.27)$ & $2.98(0.29)$ & $3.04(0.31)$ & $3.67(0.33)$ & $3.58(0.33)$ & $3.68(0.32)$ \\
\hline Moisture release & $4.00(0.32)$ & $4.15(0.31)$ & $3.93(0.29)$ & $4.33(0.34)$ & $3.35(0.29)$ & $3.42(0.27)$ & $3.28(0.27)$ & $3.26(0.25)$ \\
\hline Mouth coating & $3.95(0.29)$ & $4.17(0.32)$ & $4.04(0.32)$ & $4.42(0.33)$ & $3.63(0.31)$ & $4.04(0.32)$ & $4.67(0.29)$ & $4.17(0.36)$ \\
\hline Chewiness & $3.02(0.30)$ & $3.57(0.34)$ & $3.74(0.28)$ & $3.67(0.29)$ & $3.66(0.29)$ & $3.93(0.34)$ & $4.18(0.27)$ & $3.95(0.33)$ \\
\hline Astringency & $2.00(0.23)$ & $2.52(0.35)$ & $1.73(0.22)$ & $2.52(0.29)$ & $2.07(0.24)$ & $2.50(0.38)$ & $1.73(0.18)$ & $2.51(0.33)$ \\
\hline Residual & $2.97(0.30)$ & $3.03(0.30)$ & $2.93(0.33)$ & $3.19(0.32)$ & $2.78(0.26)$ & $3.24(0.35)$ & $2.69(0.30)$ & $3.15(0.32)$ \\
\hline
\end{tabular}




\section{Table 4}

Significance of the distances between the Manzanilla and Hojiblanca black ripe olive samples as evaluated by the $p$-values of the Hotelling- 2 tests. Significant distances $(p \leq 0.05)$ in bold. Notes: HA1 (cultivar, Hojiblanca; growing area, Alameda (Málaga); storage period, one month), HA2 (Hojiblanca; Alameda; seven months), HL1 (Hojiblanca; Lora de Estepa (Sevilla); one month), HL2 (Hojiblanca; Lora de Estepa (Sevilla); seven months), MAL1 (Manzanilla; Aljarafe (Sevilla); one month), MAL2 (Manzanilla; Aljarafe (Sevilla); seven months), ML1 (Manzanilla; Lora de Estepa (Sevilla); one month), ML2 (Manzanilla; Lora de Estepa (Sevilla); seven months).

a) Using the raw data directly

\begin{tabular}{lllllllll}
\hline & HA1 & HA2 & HL1 & HL2 & MAL1 & MAL2 & ML1 & ML2 \\
\hline HA1 & 1 & $\mathbf{0 . 0 4 4 8 1}$ & 0.5359 & 0.09464 & $\mathbf{1 . 5 3 5 e - 0 5}$ & $\mathbf{4 . 1 2 e - 0 5}$ & $\mathbf{5 . 1 5 5 e - 0 5}$ & $\mathbf{1 . 0 3 1 e - 0 6}$ \\
\hline HA2 & $\mathbf{0 . 0 4 4 8 1}$ & 1 & 0.1789 & 0.9813 & $\mathbf{0 . 0 0 0 1 3 6 9}$ & $\mathbf{0 . 0 0 2 3 3 9}$ & $\mathbf{0 . 0 0 0 5 1 3 7}$ & $\mathbf{3 . 5 3 4 e - 0 5}$ \\
\hline HL1 & 0.5359 & 0.1789 & 1 & 0.2852 & $\mathbf{0 . 0 0 0 9 6 9 7}$ & $\mathbf{0 . 0 0 0 5 5 1 7}$ & $\mathbf{0 . 0 0 2 1 6 9}$ & $\mathbf{1 . 7 7 6 e - 0 5}$ \\
\hline HL2 & 0.09464 & 0.9813 & 0.2852 & 1 & $\mathbf{0 . 0 0 0 6 7 5 7}$ & $\mathbf{0 . 0 1 0 3 9}$ & $\mathbf{0 . 0 0 2 5 1}$ & $\mathbf{0 . 0 0 0 4 1 7}$ \\
\hline MAL1 & $\mathbf{1 . 5 3 5 e - 0 5}$ & $\mathbf{0 . 0 0 0 1 3 6 9}$ & $\mathbf{0 . 0 0 0 9 6 9 7}$ & $\mathbf{0 . 0 0 0 6 7 5 7}$ & 1 & $\mathbf{0 . 0 2 7 2 4}$ & 0.4563 & $\mathbf{0 . 0 0 2 3 4 3}$ \\
\hline MAL2 & $\mathbf{4 . 1 2 e - 0 5}$ & $\mathbf{0 . 0 0 2 3 3 9}$ & $\mathbf{0 . 0 0 0 5 5 1 7}$ & $\mathbf{0 . 0 1 0 3 9}$ & $\mathbf{0 . 0 2 7 2 4}$ & 1 & 0.09532 & 0.3166 \\
\hline ML1 & $\mathbf{5 . 1 5 5 e - 0 5}$ & $\mathbf{0 . 0 0 0 5 1 3 7}$ & $\mathbf{0 . 0 0 2 1 6 9}$ & $\mathbf{0 . 0 0 2 5 1}$ & 0.4563 & 0.09532 & 1 & $\mathbf{0 . 0 0 6 1 8 2}$ \\
\hline ML2 & $\mathbf{1 . 0 3 1 e - 0 6}$ & $\mathbf{3 . 5 3 4 e - 0 5}$ & $\mathbf{1 . 7 7 6 e - 0 5}$ & $\mathbf{0 . 0 0 0 4 1 7}$ & $\mathbf{0 . 0 0 2 3 4 3}$ & 0.3166 & $\mathbf{0 . 0 0 6 1 8 2}$ & 1 \\
\hline
\end{tabular}

b) Using centred data

\begin{tabular}{|c|c|c|c|c|c|c|c|c|}
\hline & HA1 & HA2 & HL1 & $\mathrm{HL2}$ & MAL1 & MAL2 & ML1 & ML2 \\
\hline HA1 & 1 & $3.43 e-06$ & 0.01616 & 0.0004547 & $5.772 \mathrm{e}-08$ & $3.702 \mathrm{e}-08$ & $4.94 \mathrm{e}-09$ & $1.983 e-12$ \\
\hline $\mathrm{HA} 2$ & $3.43 e-06$ & 1 & 0.001357 & 0.3516 & $9.11 \mathrm{e}-12$ & $3.047 e-06$ & $1.46 \mathrm{e}-09$ & $1.414 \mathrm{e}-10$ \\
\hline HL1 & 0.01616 & 0.001357 & 1 & 0.07326 & $4.892 \mathrm{e}-07$ & $7.092 \mathrm{e}-05$ & $9.373 e-06$ & $1.37 \mathrm{e}-08$ \\
\hline $\mathrm{HL2}$ & 0.0004547 & 0.3516 & 0.07326 & 1 & $1.339 \mathrm{e}-09$ & 0.0001344 & $1.509 \mathrm{e}-07$ & $6.729 \mathrm{e}-08$ \\
\hline MAL1 & $5.772 \mathrm{e}-08$ & $9.11 \mathrm{e}-12$ & $4.892 \mathrm{e}-07$ & $1.339 \mathrm{e}-09$ & 1 & 0.002497 & 0.3649 & $7.502 \mathrm{e}-07$ \\
\hline MAL2 & $3.702 \mathrm{e}-08$ & $3.047 e-06$ & $7.092 \mathrm{e}-05$ & 0.0001344 & 0.002497 & 1 & 0.01792 & 0.03368 \\
\hline ML1 & $4.94 \mathrm{e}-09$ & $1.46 \mathrm{e}-09$ & $9.373 e-06$ & $1.509 \mathrm{e}-07$ & 0.3649 & 0.01792 & 1 & $3.39 \mathrm{e}-06$ \\
\hline ML2 & $1.983 e-12$ & $1.414 \mathrm{e}-10$ & $1.37 \mathrm{e}-08$ & $6.729 \mathrm{e}-08$ & $7.502 \mathrm{e}-07$ & 0.03368 & $3.39 \mathrm{e}-06$ & 1 \\
\hline
\end{tabular}

b) Using centred data and a 30 panel members

\begin{tabular}{|c|c|c|c|c|c|c|c|c|}
\hline & HA1 & HA2 & HL1 & HL2 & MAL1 & MAL2 & ML1 & ML2 \\
\hline HA1 & 1 & $7.143 e-13$ & 0.000113 & $4.035 \mathrm{e}-08$ & $7.251 \mathrm{e}-17$ & $2.663 \mathrm{e}-17$ & $2.818 \mathrm{e}-19$ & $5.714 \mathrm{e}-27$ \\
\hline HA2 & $7.143 e-13$ & 1 & $4.613 e-07$ & 0.1009 & $1.816 \mathrm{e}-25$ & $5.476 e-13$ & $1.79 \mathrm{e}-20$ & $9.087 \mathrm{e}-23$ \\
\hline HL1 & 0.000113 & $4.613 e-07$ & 1 & 0.003193 & $8.951 \mathrm{e}-15$ & $6.355 \mathrm{e}-10$ & $6.824 \mathrm{e}-12$ & $2.821 \mathrm{e}-18$ \\
\hline $\mathrm{HL2}$ & $4.035 e-08$ & 0.1009 & 0.003193 & 1 & $1.472 \mathrm{e}-20$ & $2.653 e-09$ & $6.33 e-16$ & $1.025 \mathrm{e}-16$ \\
\hline MAL1 & $7.251 \mathrm{e}-17$ & $1.816 \mathrm{e}-25$ & $8.951 \mathrm{e}-15$ & $1.472 \mathrm{e}-20$ & 1 & $1.792 \mathrm{e}-06$ & 0.1096 & $2.343 e-14$ \\
\hline MAL2 & $2.663 \mathrm{e}-17$ & $5.476 \mathrm{e}-13$ & $6.355 \mathrm{e}-10$ & $2.653 e-09$ & $1.792 \mathrm{e}-06$ & 1 & 0.0001421 & 0.000574 \\
\hline ML1 & $2.818 \mathrm{e}-19$ & $1.79 \mathrm{e}-20$ & $6.824 \mathrm{e}-12$ & $6.33 e-16$ & 0.1096 & 0.0001421 & 1 & $6.958 \mathrm{e}-13$ \\
\hline ML2 & $5.714 \mathrm{e}-27$ & $9.087 e-23$ & $2.821 \mathrm{e}-18$ & $1.025 e-16$ & $2.343 e-14$ & 0.000574 & $6.958 \mathrm{e}-13$ & 1 \\
\hline
\end{tabular}



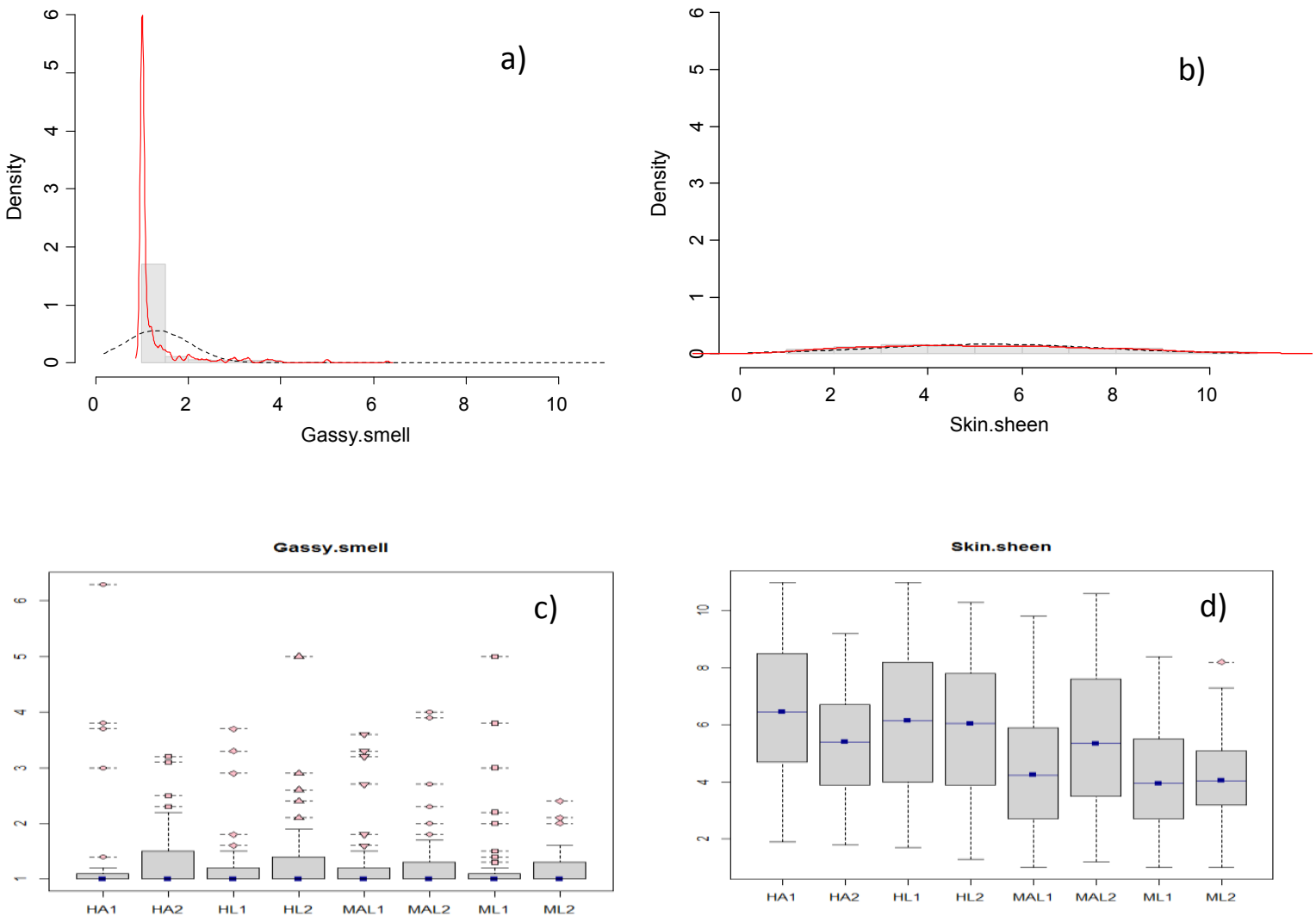

Fig. 1 

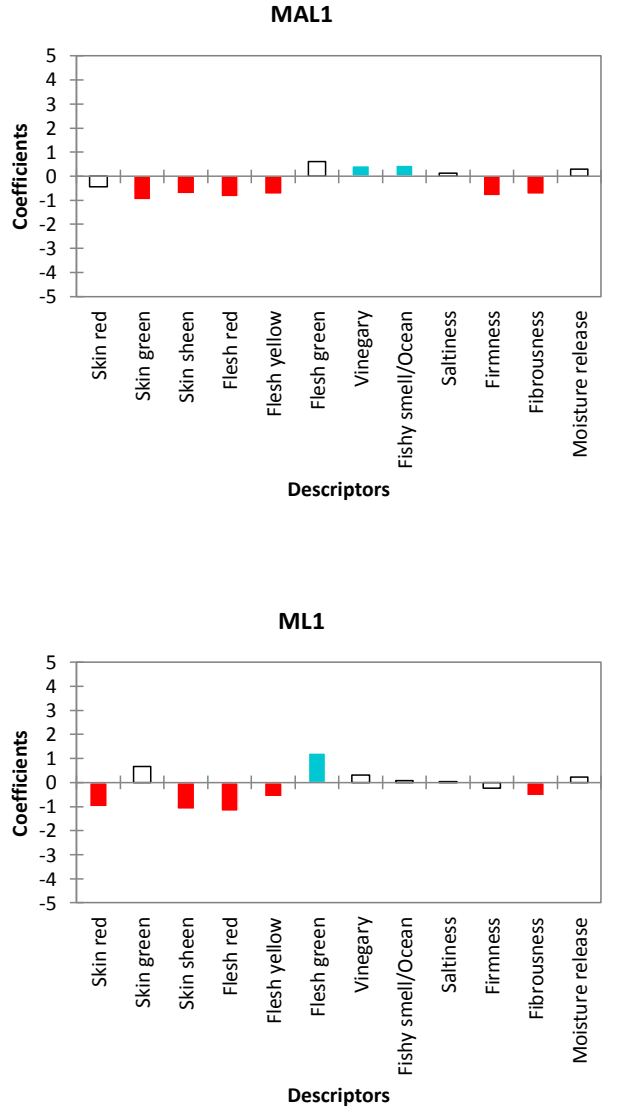
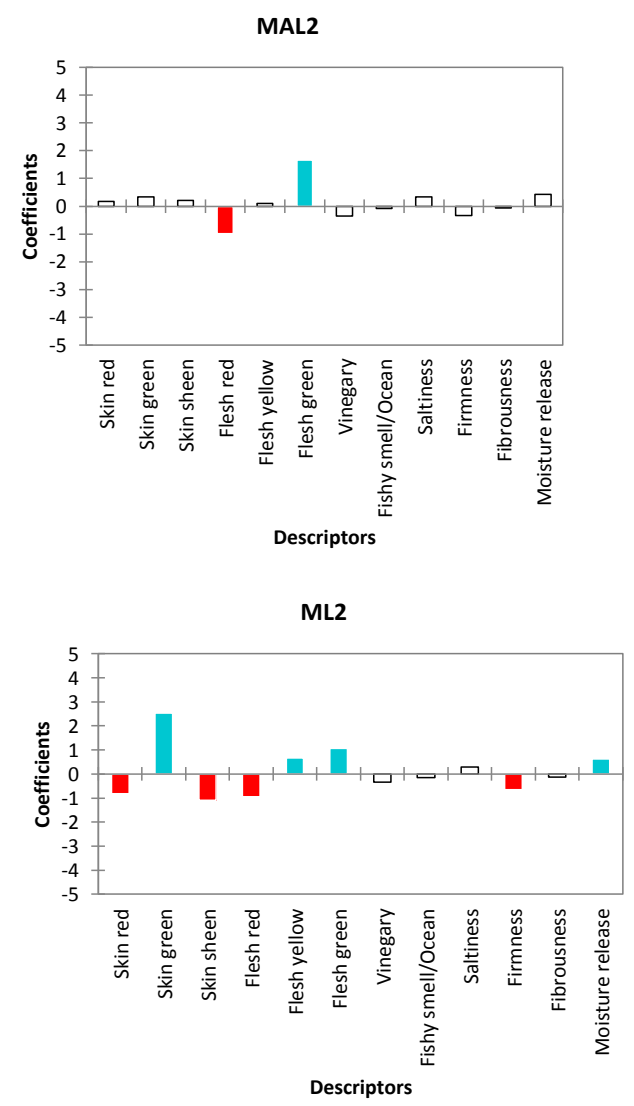

Fig.2 

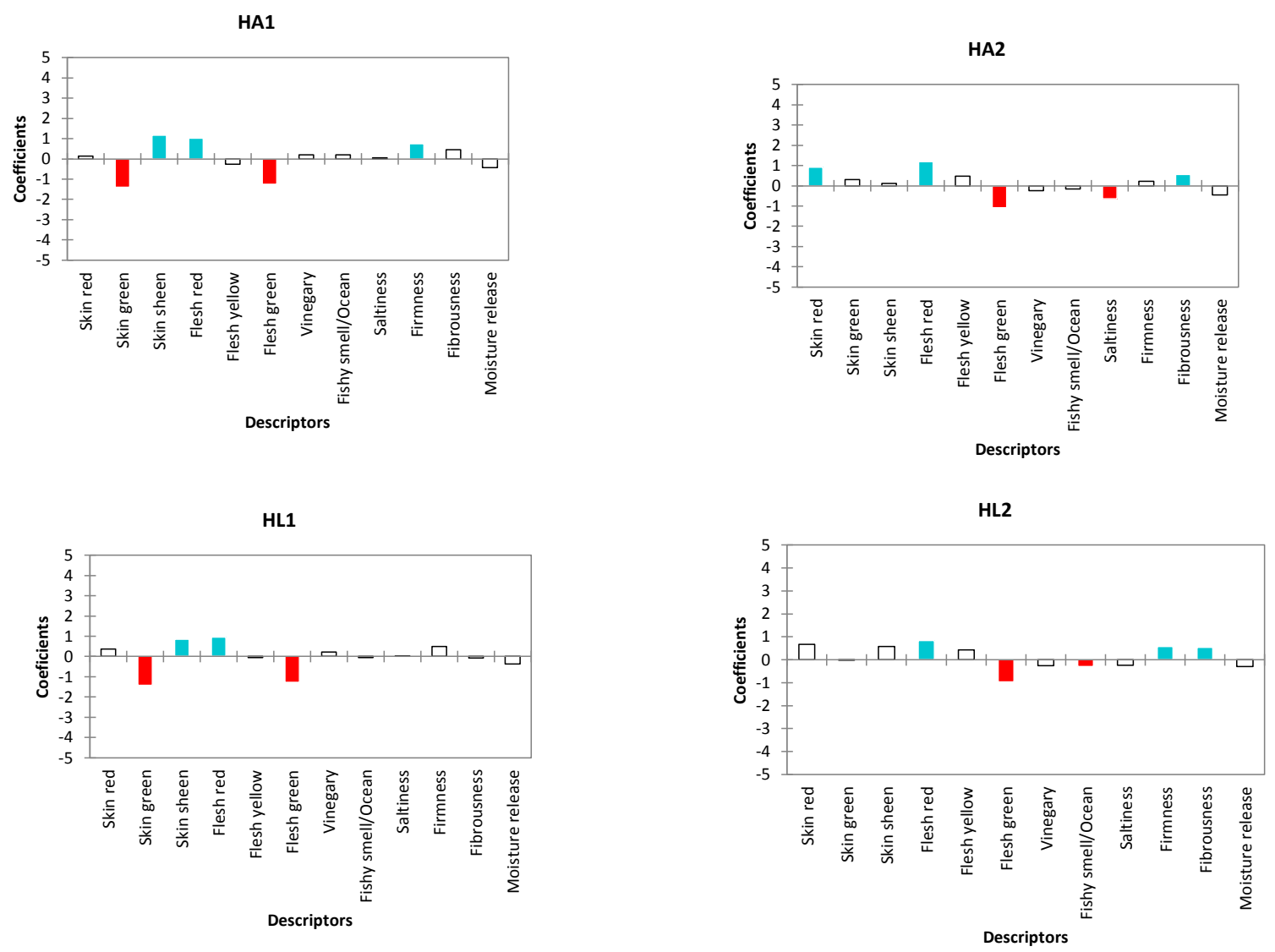

Fig.3 
a)

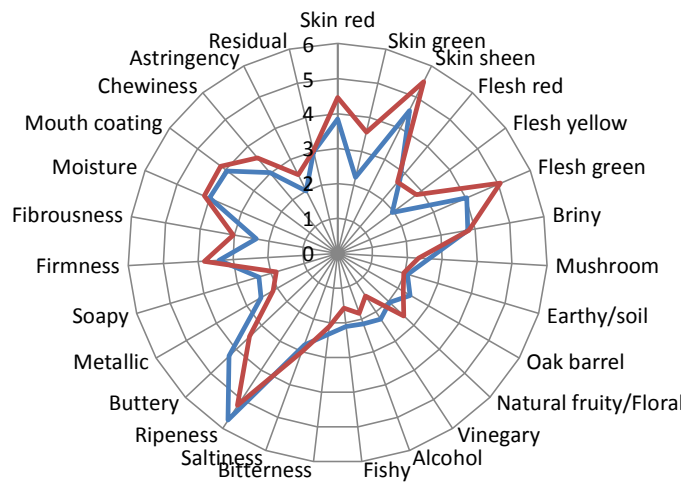

MAL1 $=$ MAL2

c)

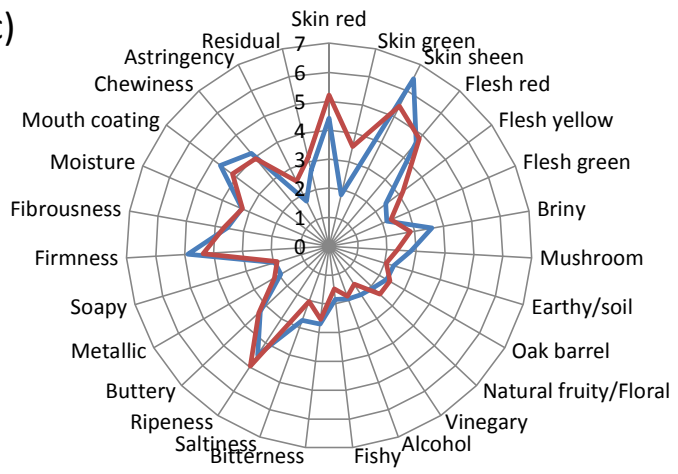

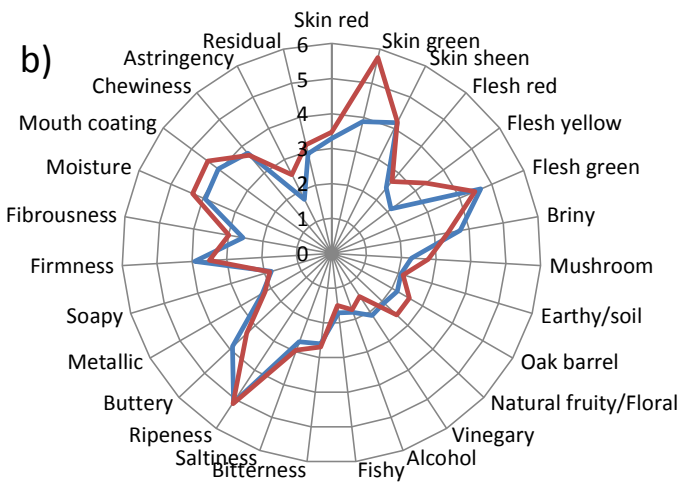

$\longrightarrow \mathrm{ML1}=\mathrm{ML2}$

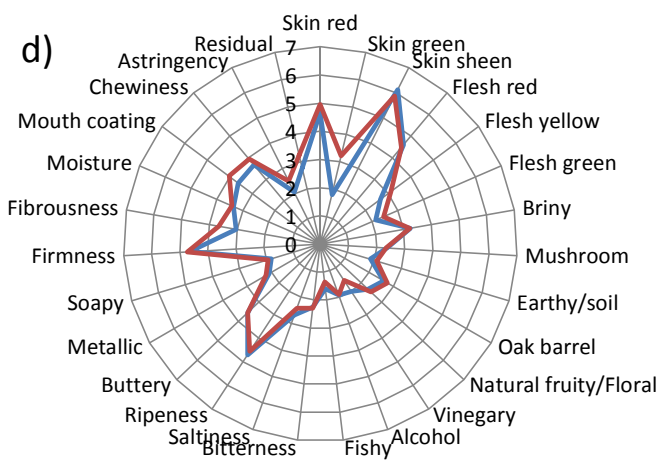

$\longrightarrow \mathrm{HL} 1-\mathrm{HL} 2$

Fig.4 

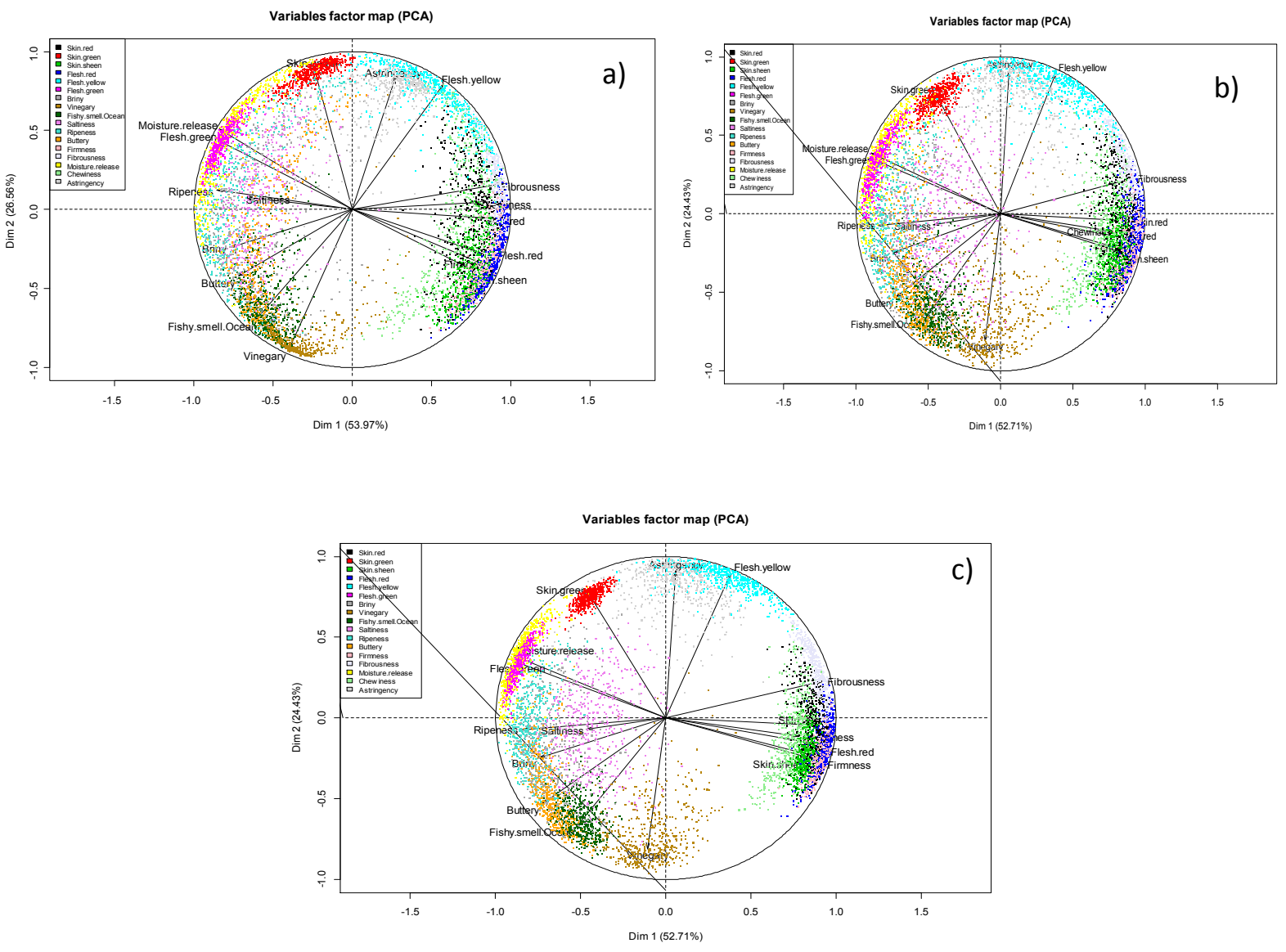

Fig.5 

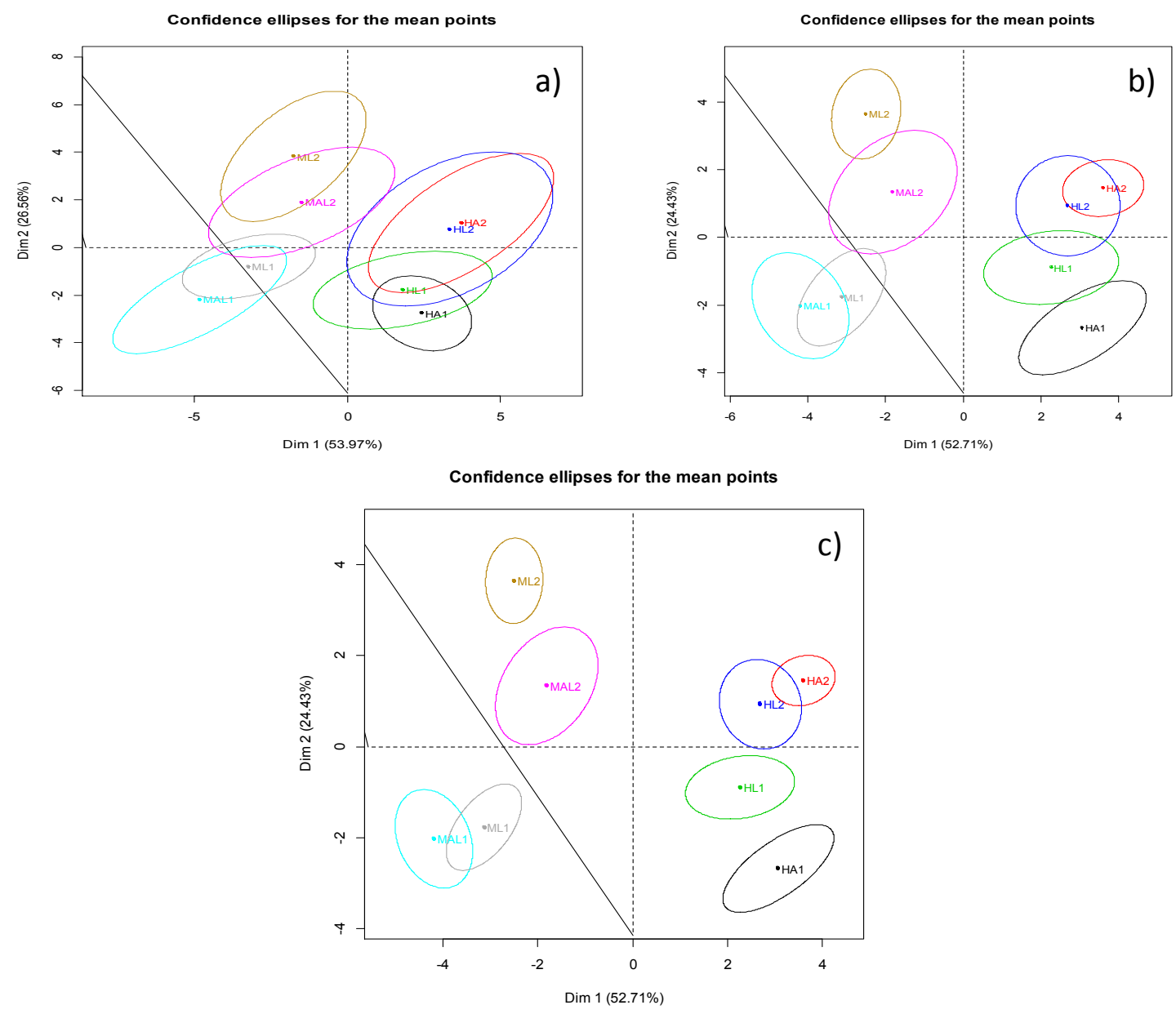

Fig.6 


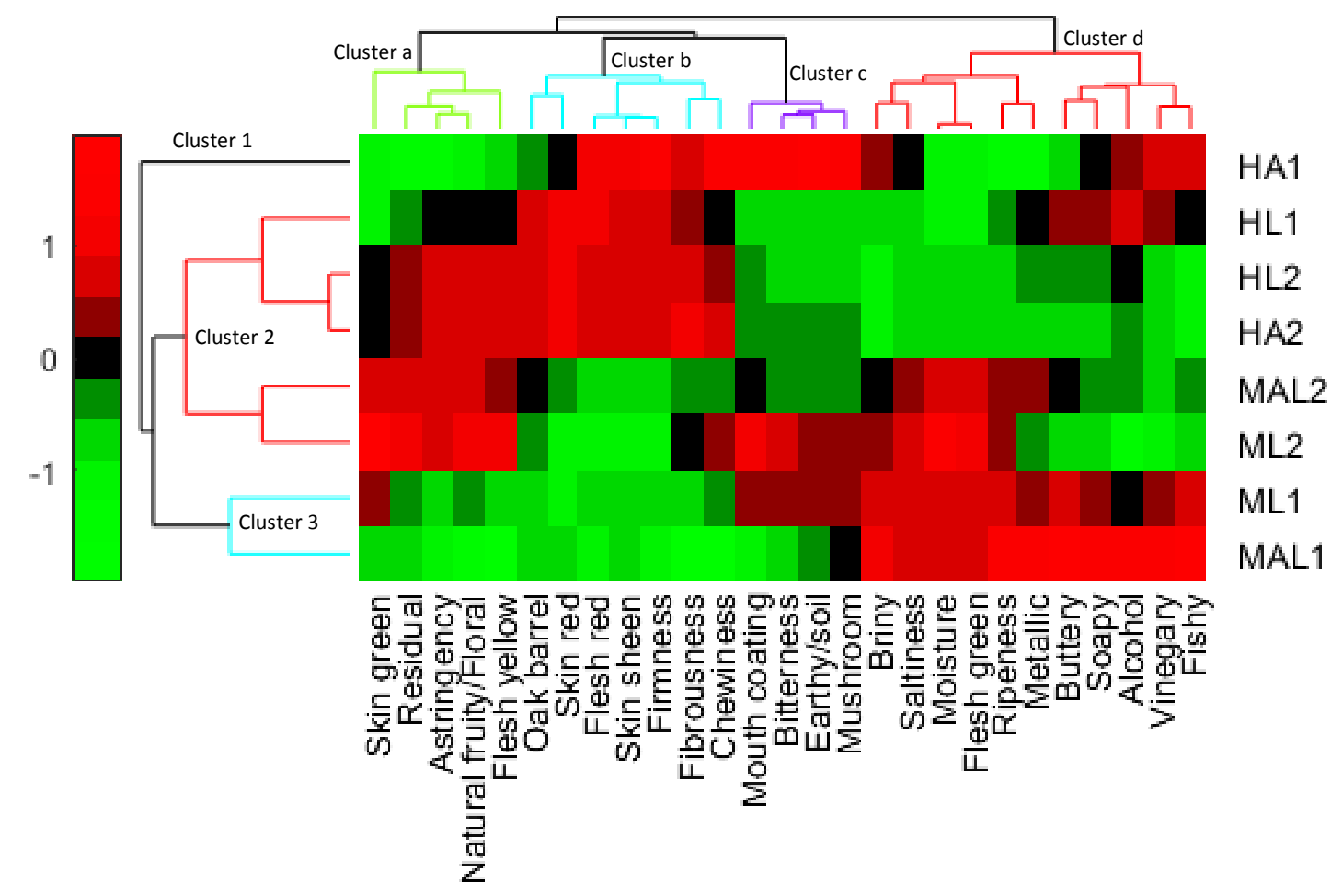

Fig.7 